Bull. Chem. Soc. Ethiop. 2019, 33(2), 359-372.

ISSN 1011-3924

(c) 2019 Chemical Society of Ethiopia and The Authors

Printed in Ethiopia

DOI: https://dx.doi.org/10.4314/bcse.v33i2.16

\title{
AMINO-SUBSTITUTED NAPHTHALENE SULFONIC ACID/GRAPHENE COMPOSITE AS METAL -FREE CATALYSTS FOR OXYGEN REDUCTION REACTIONS
}

\author{
Teklewold Getachew ${ }^{*}$, Fitsum Addis, Taye Beyene, Solomon Mehretie, and Shimelis Admassie \\ Materials Science Program, Department of Chemistry/Addis Ababa University, P.O. Box 1176, \\ Addis Ababa, Ethiopia
}

(Received September 22, 2018; Revised April 25, 2019; Accepted May 13, 2019)

\begin{abstract}
Composites of reduced graphene oxide (rGO) and conducting polymers synthesized from 8amino-2-naphthalene sulfonic acid (8-ANSA), 5-amino-1-naphthalene sulfonic acid (5-ANSA), 2-amino-1naphthalene sulfonic acid (2-ANSA), and 4-amino-1-naphthalene sulfonic (4-ANSA) were prepared for use as an electrocatalyst in oxygen reduction reaction (ORR). The electrocatalytic activities were examined in oxygen saturated $0.1 \mathrm{M} \mathrm{KOH}$ solution using cyclic and linear sweep voltammetry. The best performing polymer composite was found to be GC/poly(8-ANSA)/rGO, with an enhanced electrocatalytic activity over the rGO only and poly(8-ANSA) only films. More than $100 \mathrm{mV}$ positive shift in the onset potential and 1.6 times increase in current density were observed. The catalytic activity of 2-ANSA, 4-ANSA, 5-ANSA, and 8-ANSA was also validated by density functional theory (DFT). Our calculations predict a much better catalytic activity for 8-ANSA than that of 2-ANSA, 4-ANSA, and 5-ANSA.
\end{abstract}

KEY WORDS: Poly(amino naphthalene sulfonic acid), Reduced graphene oxide, Oxygen reduction reaction, Electrocatalyst

\section{INTRODUCTION}

Oxygen reduction reaction (ORR) is one of the most important reactions in a fuel cell, metal-air batteries, chloroalkali electrolyzer, metal corrosion, sensors, industrial electrolytic process and electro-organic reactions [1-3]. However, ORR is kinetically sluggish, involves several steps and many intermediates which makes challenging for researchers in the field. The most efficient catalyst generally considered so far for ORR are noble metals such as platinum (Pt) and its alloy. Nevertheless, these catalysts have a high price, scarce, poor durability, poor tolerance for $\mathrm{CO}$ poisoning and methanol crossover. In order to overcome these challenges researchers explore and develop non-precious metals or metal-free catalysts for ORR [1, 4-6].

Graphene is becoming a promising candidate for ORR electrocatalysts due to their excellent conductivity, unique specific surface area, and customized surface chemistry [7,8]. Graphite oxide has become the most common precursor for the cost-effective and mass production of graphene-based materials. Graphene oxide $(\mathrm{GO})$ needs reduction to restore the disrupted $\pi$ system/ $\mathrm{sp}^{2}$ hybridized network using chemical or electrochemical reduction or thermal annealing. The electrochemical reduction method is advantageous over the other in that it is simple, fast, and doesn't require the use of any toxic reducing agents. Reduced graphene oxide (rGO) sheet shows low dispersibility in solvents and tends to restack as a graphite-like structure due to the removal of most of the oxygen functionalities. This aggregation of the rGO sheets reduces the available surface area, limits electron and ion transport which resulted in poor electrochemical performance. One applied strategy to solve this problem is the composite formation of rGO with conducting polymers. The most commonly used conducting polymers are polypyrrole, polyaniline, polythiophene and their derivatives [9-12].

In recent years, graphene composited with poly(3,4-ethylenedioxythiophene): poly(styrenesulfonate) (PEDOT:PSS) [13], polypyrrole [14], polyaniline [15, 16] has been

*Corresponding author. teshtu@yahoo.com

This work is licensed under the Creative Commons Attribution 4.0 International License 
reported as an electrocatalyst for ORR. In this work, composite films of amino-substituted naphthalene sulfonic acid based polymers and graphene layers were synthesized for metal-free electrocatalyst for oxygen reduction reaction in alkaline media. Enhanced durability for metalfree over metal catalysts is observed in alkaline media [17].

We previously reported [18] 4-amino-3-hydroxy naphthalene sulfonic acid (AHNSA) for use in catalyzing the oxygen reduction reaction in acidic solution. However, to the best of our knowledge, graphene oxide composited with amino substituted naphthalene sulfonic acids have never been prepared and examined for electrocatalysis in the oxygen reduction reaction.

\section{EXPERIMENTAL}

\section{Reagents and apparatus}

Sodium nitrate, potassium chloride, nitric acid, 8-amino-2-naphthalene sulfonic acid (8-ANSA), 5-amino-1-naphthalene sulfonic acid (5-ANSA), 2-amino-1-naphthalene sulfonic acid (2ANSA) and 4-amino-1-naphthalene sulfonic (4-ANSA) were purchased from Sigma Aldrich. Sulfuric acid and hydrochloric acid were obtained from Carlo Erba Reagents. Potassium permanganate and potassium hydroxide were obtained from BDH Chemicals Ltd. Hydrogen peroxide, potassium nitrate, potassium hexacyanoferrate(III) and graphite was purchased from Riedel de Haen. Nitrogen and oxygen gases were purchased in cylinders from Chora Gas \& Chemical Product Factory.

$\mathrm{X}$-ray diffraction spectra were prepared on MiniFlex X-ray diffractometer using $\mathrm{Cu}-\mathrm{K} \alpha$ radiation $(\lambda=0.15406 \mathrm{~nm})$. PerkinElmer Spectrum 65 FT-IR Spectrometer was used to record the infrared spectra.

A potentiostat/galvanostat (Autolab PGSTAT 128N) connected to a computer with general purpose electrochemical system (GPES v 4.9) and Nova (version 1.9.16) software is used to characterize the electrochemical properties of the electrocatalysts using a rotating disk glassy carbon (RDGC) working electrode $\left(0.196 \mathrm{~cm}^{2}\right)$. Rotating ring-disk electrode (RRDE) measurements were carried out at room temperature on a Pine bipotentiostat (model AFCBP1) connected to a computer with aftermath (version 1.2.5033) software. Glassy carbon disk electrode $\left(0.2472 \mathrm{~cm}^{2}\right)$ surrounded by a Pt ring $\left(0.1859 \mathrm{~cm}^{2}\right)$ were used for RRDE measurements. Silver/silver chloride $(\mathrm{Ag} / \mathrm{AgCl}, 3 \mathrm{M} \mathrm{KCl})$ and a platinum wire served as reference and counter electrodes, respectively. Pine rotation speed controller (AFMSRCE 2957) was used during the rotating disk electrode (RDE) and RRDE measurements.

\section{Synthesis of $G O$}

Graphene oxide was synthesized from graphite powder using modified Hummer's method [19]. Specifically, graphite powder $(1 \mathrm{~g})$ and sodium nitrate $(0.5 \mathrm{~g})$ were mixed together and added to concentrated sulphuric acid $(23 \mathrm{~mL})$ in a beaker under constant stirring at room temperature. The beaker was put in an ice bath for cooling to $0{ }^{\circ} \mathrm{C}$ under constant stirring for one hour, and potassium permanganate $(3 \mathrm{~g})$ was added gradually to the mixture while keeping the temperature less than $20^{\circ} \mathrm{C}$. The mixture was stirred in a water bath at $35^{\circ} \mathrm{C}$ for 6 hours to form a thick paste and the resulting solution was diluted by adding $500 \mathrm{~mL}$ of water under vigorous stirring. Subsequently, the suspension was further treated with $30 \% \mathrm{H}_{2} \mathrm{O}_{2}$ solution $(5 \mathrm{~mL})$ to terminate the reaction. The resulting mixture was washed with $1: 10 \mathrm{HCl}$ aqueous solution followed by filtration. The collected solid material was dried in a vacuum oven to obtain GO.

\section{Electrochemical reduction of $G O$}

Five $\mathrm{mg}$ GO was dispersed in $10 \mathrm{~mL}$ deionized water and ultrasonicated for $1 \mathrm{~h} .20 \mu \mathrm{L}$ of the graphene oxide dispersion $\left(0.5 \mathrm{mg} \mathrm{mL}^{-1}\right)$ was drop-casted onto the pre-polished glassy carbon 
Amino-substituted naphthalene sulfonic acid/graphene composite as metal-free catalysts 361

electrode (GC) or on polymer modified GC (GC/poly(ANSA)) and was left to dry slowly in air. After drying, $3 \mu \mathrm{L} 0.05 \mathrm{wt} \%$ Nafion solution was applied to the surface of the resulting electrode to improve the adhesion of the film to the electrode surface. The electrochemical reduction of GO to $\mathrm{rGO}$ was carried out with cyclic voltammetry in the potential range 0 to -1.5 $\mathrm{V} v s \mathrm{Ag} / \mathrm{AgCl}$ at a scan rate of $50 \mathrm{mV} \mathrm{s}^{-1}$ in $\mathrm{N}_{2}$ saturated $0.1 \mathrm{M} \mathrm{Na}_{2} \mathrm{SO}_{4}$ for 20 cycles $[10,20]$.

\section{Electropolymerization}

Electropolymerization of $2 \mathrm{mM}$ of the monomers (8-ANSA, 2-ANSA, 4-ANSA and 5-ANSA) on bare glassy carbon electrode (GC) or on $\mathrm{GC} / \mathrm{rGO}$ in $0.1 \mathrm{M} \mathrm{HNO}_{3}$ was performed using cyclic voltammetry by scanning the potential between $-0.8 \mathrm{~V}$ and $2.0 \mathrm{~V} v \mathrm{~s} \mathrm{Ag} / \mathrm{AgCl}$ at a scan rate of $100 \mathrm{mV} \mathrm{s}^{-1}$ for 16 cycles. Then, the modified electrode was stabilized for 24 cycles in monomer free $0.5 \mathrm{M} \mathrm{H}_{2} \mathrm{SO}_{4}$ until a stable cyclic voltammogram was obtained [18].

\section{Electrochemical measurements}

The oxygen reduction currents were recorded in oxygen saturated $0.1 \mathrm{M} \mathrm{KOH}$. Cyclic and linear sweep voltammograms were recorded at a scan rate of $20 \mathrm{mV} \mathrm{s}^{-1}$. For the RRDE measurement, the disk and ring currents were recorded as a function of the disk potential scanned between -0.7 $\mathrm{V}$ and $0.1 \mathrm{~V} v s . \mathrm{Ag} / \mathrm{AgCl}$ at $10 \mathrm{mV} \mathrm{s}^{-1}$ at one rotation speed $(1600 \mathrm{rpm})$. The ring electrode potential was held at $+1 \mathrm{~V} v s$. $\mathrm{Ag} / \mathrm{AgCl}$ [13]. The collection efficiency $(\mathrm{N})$ was determined using $1 \mathrm{M} \mathrm{KNO}_{3}$ and $10 \mathrm{mM} \mathrm{K}_{3} \mathrm{Fe}(\mathrm{CN})_{6}$ deaerated with pure nitrogen. The measured collection efficiency was found to be $38 \pm 1.5 \%$.

The oxygen reduction currents were normalized to the geometric area of the electrode and corrected for the background electrode current recorded in pure nitrogen saturated $0.1 \mathrm{M} \mathrm{KOH}$ solution [21].

\section{Computational details}

All calculations were carried out with the Gaussian 16 program package [22]. The B3LYP 2325] functional together with the $6-311++G(d, p)$ basis sets [26] were used. Solvent effects were corrected by using the polarizable continuum model (PCM) in its integral equation formalism [27] together with water as a solvent. Vibrational frequency analyses were performed to verify that the optimized structures are minima without an imaginary frequency and to obtain the free energies of the dimers and their complexes. The natural bond orbital (NBO) analysis [28-29] was used to explore the charges on the atoms before and after the adsorption of the molecular oxygen on the dimers.

\section{RESULTS AND DISCUSSION}

The XRD spectra of graphite and GO were recorded in order to verify the structural changes occurring during the conversion of graphite to GO and are shown in Figure 1A. The intense sharp peak $\left(2 \theta=26.6^{\circ}\right)$ for graphite powder (Figure 1A(a)) corresponding to the $\left(\begin{array}{lll}0 & 0 & 2\end{array}\right)$ [30] reflection plane disappeared and shifted to a lower $2 \theta$ angle of $11.4^{\circ}$ after being oxidized to GO (Figure $1 \mathrm{~A}(\mathrm{~b})$ ). The shift is attributed to the intercalation of oxygen-containing groups during oxidation with $\mathrm{KMnO}_{4}$ [31]. An interlayer distance of $\sim 0.78 \mathrm{~nm}$ was calculated using Bragg's equation for $\mathrm{GO}$, which is larger than that of graphite powder $(\sim 0.34 \mathrm{~nm})$. The small peak (Figure $1 \mathrm{~A}(\mathrm{~b})$ ) at $2 \theta=42.6^{\circ}$ is corresponding to the (100) in plane hexagonal atom arrangement [32]. 

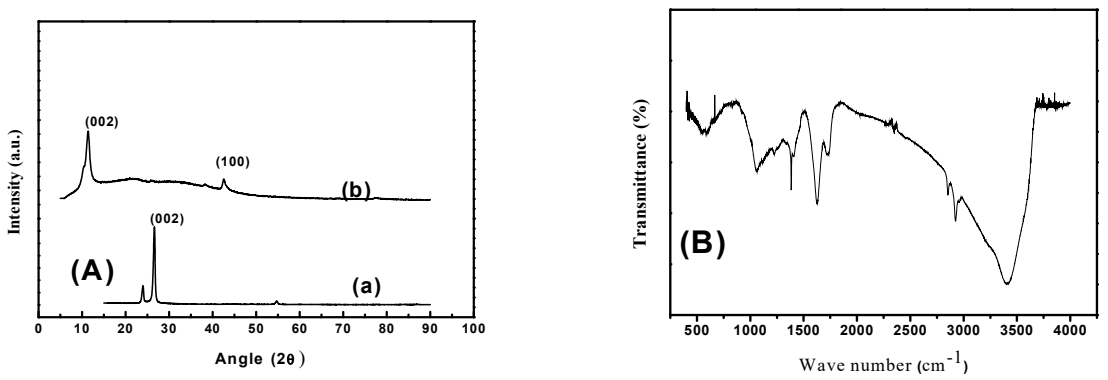

Figure 1. (A) XRD patterns of (a): graphite, (b): GO and (B) FT-IR spectra of GO.

The FTIR spectra of GO (Figure 1B) shows several characteristic peaks. A broad and intense peak at $3414 \mathrm{~cm}^{-1}$ attributed to $\mathrm{O}-\mathrm{H}$ stretching of carboxyl groups, a weak peak at $1735 \mathrm{~cm}^{-1}$ assigned to $\mathrm{C}=\mathrm{O}$ stretching of carbonyl groups, an intense peak at $1632 \mathrm{~cm}^{-1}$ corresponds to $\mathrm{C}=\mathrm{C}$ stretching, a sharp peak at $1399 \mathrm{~cm}^{-1}$ and a broad peak at 1065 $\mathrm{cm}^{-1}$ are assigned to $\mathrm{C}-\mathrm{O}$ stretching vibration of carboxyl and alkoxy group, respectively $[30,32$, 33].

Figure 2a shows a typical cyclic voltammograms for the electropolymerization of 8-ANSA on a polished glassy carbon rotating disk electrode. During the first cycle, anodic and cathodic peaks at $0.78 \mathrm{~V}$ and $-0.0811 \mathrm{~V}$, respectively, were observed. In the successive scans, three new anodic peaks appeared at $0.251 \mathrm{~V}, 0.332 \mathrm{~V}$, and $0.6139 \mathrm{~V}$. Unlike the peak at $0.78 \mathrm{~V}$ which is due to the redox activity of the monomer [34], all the peaks increase with increasing number of cycles which shows the formation of polymer film on the surface of the glassy carbon electrode (GC) [18].
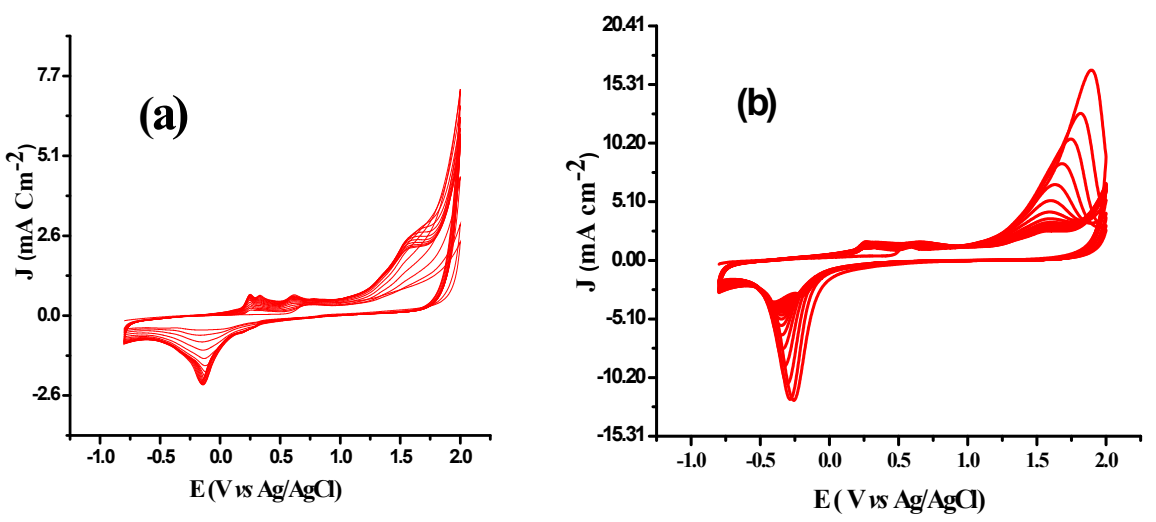

Figure 2. Cyclic voltammograms obtained for the electropolymerization of (a) 8-ANSA on GC and (b) 8-ANSA on GC/rGO from a solution containing $2 \mathrm{mM} 8$-ANSA monomer in $0.1 \mathrm{M} \mathrm{HNO}_{3}$ at a scan rate of $100 \mathrm{mV} \mathrm{s}^{-1}$ for 16 scans between $-0.8 \mathrm{~V}$ to $2.0 \mathrm{~V}$ vs $\mathrm{Ag} / \mathrm{AgCl}$.

Peak currents for the potentiodynamic polymerization of 8-ANSA onto rGO (Figure 2b) coated electrodes are higher than those on the surface of the glassy carbon electrode since modification by rGO leads to a larger electroactive surface area. 

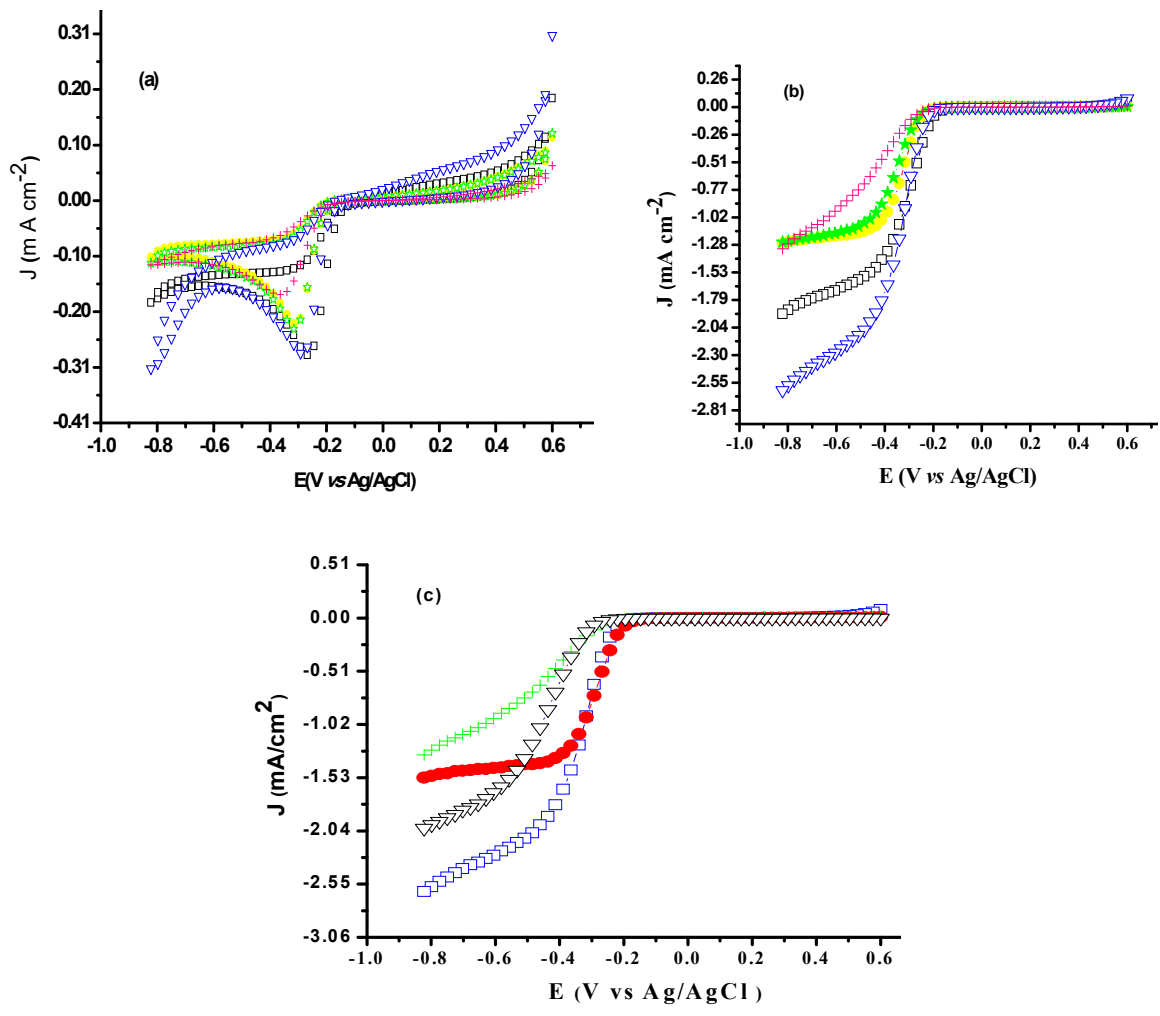

Figure 3. Comparison of the background corrected (a) cyclic voltammogramms and (b) linear sweep voltammograms of $(+) \mathrm{GC} / \mathrm{rGO},(\star)$ GC/poly(5-ANSA)/rGO, $(\bullet)$ GC/poly(4ANSA)/rGO, ( $\square$ )GC/poly(2-ANSA)/rGO, and ( $\nabla)$ GC/poly(8-ANSA)/rGO (c) linear sweep voltammograms of (+) GC/rGO, ( $\nabla)$ GC/poly(8-ANSA), ( $\square)$ GC/poly (8ANSA)/rGO, and $(\bullet) \mathrm{GC} / \mathrm{rGO} /$ poly(8-ANSA) electrodes in $0.1 \mathrm{M} \mathrm{KOH}$ at a scan rate of $20 \mathrm{mV} \mathrm{s}^{-1}$ in $0.1 \mathrm{M} \mathrm{KOH}$. Rotational rate for LSV measurements were $1600 \mathrm{rpm}$.

After the electrosynthesis of all the monomers (8-ANSA, 2-ANSA, 4-ANSA, and 5-ANSA) on bare RDGC electrode under similar conditions, electrochemical reduction of GO on polymer modified GC electrodes were performed. Cyclic (CV) and linear sweep(LSV) voltammetry measurements were performed in $\mathrm{O}_{2}$-saturated $0.1 \mathrm{M} \mathrm{KOH}$ to compare the electrocatalytic activity of the four different amino substituted naphthalene sulfonic acid polymers composited with rGO. rGO modified GC electrode was also used in the comparison as a reference. The results are depicted in Figure 3a,b. The ORR activity for all the polymers-rGO modified GC electrode was found to be higher than that of $\mathrm{GC} / \mathrm{rGO}$. The onset potentials of GC/poly(2ANSA)/rGO and GC/poly(8-ANSA)/rGO were more positive compared to that of GC/poly(4ANSA)/rGO and GC/poly(5-ANSA)/rGO composite films. In terms of the current density, GC/poly(8-ANSA)/rGO has the highest value among all the polymers. Thus, GC/poly(8ANSA)/rGO composite was chosen for further analysis.

The reaction mechanism of oxygen reduction involves diffusion in the bulk of the electrolyte and the conducting films, adsorption process, and electron transfer [35]. Any of these processes might be rate controlling and can be one of the criteria for the catalytic activity of materials. To 
explain the catalytic activity of poly(5-ANSA), poly(4-ANSA), poly(2-ANSA), and poly(8ANSA), quantum-chemical calculations of the electronic structure for all the amino substituted naphthalene sulfonic acid and their adsorption complexes with molecular oxygen were performed using density functional theory (DFT). The dimers (Figure 4) and their adsorption complexes with oxygen were used for all the calculations. To identify the adsorption sites, we used the natural charges from the natural bond orbital (NBO) analysis. From the results in Table 1 , the maximum negative change are concentrated on carbon atoms in positions $\mathrm{C}_{3}, \mathrm{C}_{4}, \mathrm{C}_{8}, \mathrm{C}_{9}$, $\mathrm{C}_{14}, \mathrm{C}_{15}, \mathrm{C}_{17}$, and $\mathrm{C}_{18}$. Each carbon atoms can in principle be an adsorption site for oxygen binding, however, the carbon atoms with larger negative charges are more preferable for the oxygen adsorption. The results listed in Table 1 show a clear increase in the negative charge on $\mathrm{O}_{2}$ (from 0.0 to -0.367 ; see the last two rows of Table 1), and a positive charge on the adsorption sites $\left(\mathrm{C}_{8}-\mathrm{C}_{9}\right)$ in the complexes (2-ANSA-O $\mathrm{O}_{2}, 4-\mathrm{ANSA}-\mathrm{O}_{2}, 5-\mathrm{ANSA}-\mathrm{O}_{2}$, and 8ANSA- $\mathrm{O}_{2}$ ), indicating the adsorption of $\mathrm{O}_{2}$ on the dimers.

(a)<smiles></smiles>

(b)<smiles></smiles>

(d)

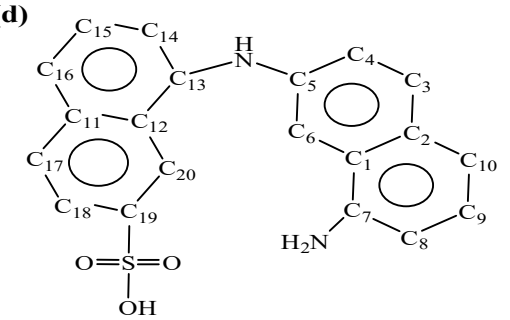

Figure 4. Dimers of (a) 2-ANSA, (b) 4-ANSA, (c) 5-ANSA, and (d) 8-ANSA molecular cluster. Hydrogen atoms were omitted for clarity.

The Gibbs free energy of formation $\left(\Delta G_{f}\right)$ (Table 2) between the oxygen atoms and the carbon atoms in the positions 8 and 9 are lower for all ANSA- $\mathrm{O}_{2}$ complexes than for other carbon atoms (e.g, $\mathrm{C}_{14}$ and $\mathrm{C}_{15}$ ). This clearly shows that positions 8 and 9 are the most preferable $\mathrm{O}_{2}$ adsorption sites.

The electron density transferred to $\mathrm{O}_{2}$ and occupies the antibonding MO's of $\mathrm{O}_{2}$ (adsorbed) which is responsible for the destabilization of the $\mathrm{O}-\mathrm{O}$ bond in $\mathrm{O}_{2}$. This is evident from the $\mathrm{O}-\mathrm{O}$ bond length which is elongated to $1.498,1.5,1.497$ and $1.492 \AA$ for 2-ANSA- $\mathrm{O}_{2}, 4-\mathrm{ANSA}-\mathrm{O}_{2}$, 5-ANSA- $\mathrm{O}_{2}$, and 8-ANSA- $\mathrm{O}_{2}$, respectively, from that of $1.21 \AA$ for the bare $\mathrm{O}_{2}$ molecule. The $\mathrm{O}-\mathrm{C}_{\mathrm{x}}$ and $\mathrm{O}-\mathrm{C}_{\mathrm{y}}$ bond lengths also show the adsorption of the $\mathrm{O}_{2}$ molecule. Thus, chemisorbed $\mathrm{O}_{2}$ molecules have a fairly high degree of activation and can be easily reduced, which accounts for the catalytic activity of the ANSA polymers. Furthermore, 8-ANSA followed by 2-ANSA, with lowest $\Delta G_{f}$ and more possible adsorption sites, are the best electrocatalytic materials for oxygen reduction reaction. This is in agreement with the experimental observation (Figure 3a.b). 
Amino-substituted naphthalene sulfonic acid/graphene composite as metal-free catalysts 365

Table 1. Natural charges obtained from the natural bond orbital (NBO) analysis in the dimers and dimer- $\mathrm{O}_{2}$ complexes (where the binding site in all dimers is $\mathrm{C}_{8}-\mathrm{C}_{9}$ ), calculated using B3LYP/6$311++\mathrm{G}(\mathrm{d}, \mathrm{p}) / \mathrm{PCM} /$ water calculations. Other possible binding sites are also shown in bold-italic fonts.

\begin{tabular}{|c|c|c|c|c|c|c|c|c|}
\hline Atom & $2-A N S A$ & $2-A N S A-\mathrm{O}_{2}$ & $4-A N S A$ & $4-A N S A-\mathrm{O}_{2}$ & $5-A N S A$ & $5-A N S A-\mathrm{O}_{2}$ & $8-A N S A$ & 8 ANSA-O \\
\hline $\mathrm{C}_{1}$ & -0.047 & -0.060 & -0.065 & -0.030 & -0.081 & -0.049 & -0.084 & -0.089 \\
\hline $\mathrm{C}_{2}$ & -0.097 & -0.073 & -0.085 & -0.051 & -0.060 & -0.029 & -0.066 & -0.102 \\
\hline $\mathrm{C}_{3}$ & $\mathbf{- 0 . 1 2 3}$ & -0.123 & 0.175 & 0.186 & 0.182 & 0.190 & $\mathbf{- 0 . 1 6 5}$ & -0.211 \\
\hline $\mathrm{C}_{4}$ & $\mathbf{- 0 . 2 3 2}$ & -0.219 & -0.301 & -0.294 & $\mathbf{- 0 . 2 4 0}$ & -0.236 & $\mathbf{- 0 . 2 2 7}$ & -0.198 \\
\hline $\mathrm{C}_{5}$ & 0.239 & 0.228 & 0.280 & 0.284 & $\mathbf{- 0 . 2 0 2}$ & -0.201 & 0.155 & 0.106 \\
\hline $\mathrm{C}_{6}$ & -0.370 & -0.333 & 0.117 & 0.088 & -0.202 & -0.234 & -0.217 & -0.202 \\
\hline $\mathrm{C}_{7}$ & -0.152 & -0.235 & -0.187 & -0.234 & 0.189 & 0.139 & 0.177 & 0.244 \\
\hline $\mathrm{C}_{8}$ & $\mathbf{- 0 . 2 0 7}$ & $\mathbf{0 . 0 7 7}$ & $\mathbf{- 0 . 2 1 9}$ & $\mathbf{0 . 0 7 1}$ & $\mathbf{- 0 . 2 7 0}$ & $\mathbf{0 . 0 7 7}$ & $\mathbf{- 0 . 2 5 2}$ & $\mathbf{0 . 0 9 8}$ \\
\hline $\mathrm{C}_{9}$ & $\mathbf{- 0 . 2 2 2}$ & $\mathbf{0 . 0 7 2}$ & $\mathbf{- 0 . 2 0 1}$ & $\mathbf{0 . 0 9 6}$ & $\mathbf{- 0 . 1 8 6}$ & $\mathbf{0 . 0 7 8}$ & $\mathbf{- 0 . 2 0 7}$ & $\mathbf{0 . 0 8 1}$ \\
\hline $\mathrm{C}_{10}$ & -0.168 & -0.122 & -0.202 & -0.164 & -0.248 & -0.213 & -0.226 & -0.205 \\
\hline $\mathrm{C}_{11}$ & -0.079 & -0.082 & -0.072 & -0.075 & -0.071 & -0.077 & -0.070 & -0.068 \\
\hline $\mathrm{C}_{12}$ & -0.050 & -0.051 & -0.051 & -0.051 & -0.043 & -0.046 & 0.013 & 0.009 \\
\hline $\mathrm{C}_{13}$ & -0.208 & -0.208 & -0.201 & -0.193 & -0.265 & -0.260 & 0.185 & 0.192 \\
\hline $\mathrm{C}_{14}$ & $\mathbf{- 0 . 1 9 5}$ & -0.193 & $\mathbf{- 0 . 1 7 0}$ & -0.183 & $\mathbf{- 0 . 1 7 4}$ & -0.190 & $\mathbf{- 0 . 2 4 3}$ & -0.254 \\
\hline $\mathrm{C}_{15}$ & $\mathbf{- 0 . 2 3 6}$ & -0.234 & $\mathbf{- 0 . 2 0 4}$ & -0.202 & $\mathbf{- 0 . 2 0 6}$ & -0.207 & $\mathbf{- 0 . 1 7 3}$ & -0.170 \\
\hline $\mathrm{C}_{16}$ & -0.162 & -0.161 & -0.191 & -0.176 & -0.149 & -0.137 & -0.217 & -0.225 \\
\hline $\mathrm{C}_{17}$ & $\mathbf{- 0 . 1 7 0}$ & -0.140 & $\mathbf{- 0 . 2 3 1}$ & -0.231 & 0.205 & 0.202 & $\mathbf{- 0 . 1 4 7}$ & -0.148 \\
\hline $\mathrm{C}_{18}$ & $\mathbf{- 0 . 2 1 7}$ & -0.237 & $\mathbf{- 0 . 2 0 5}$ & -0.207 & -0.250 & -0.255 & $\mathbf{- 0 . 2 0 5}$ & -0.206 \\
\hline $\mathrm{C}_{19}$ & 0.172 & 0.180 & 0.318 & 0.322 & -0.169 & -0.168 & -0.302 & -0.304 \\
\hline $\mathrm{C}_{20}$ & 0.077 & 0.068 & 0.120 & 0.116 & -0.224 & -0.231 & -0.175 & -0.175 \\
\hline $\mathrm{O}_{43}$ & - & $\mathbf{- 0 . 3 2 7}$ & - & $\mathbf{- 0 . 3 3 6}$ & - & $\mathbf{- 0 . 3 2 9}$ & - & $\mathbf{- 0 . 3 4 5}$ \\
\hline $\mathrm{O}_{44}$ & - & $\mathbf{- 0 . 3 3 5}$ & - & $\mathbf{- 0 . 3 3 1}$ & - & $\mathbf{- 0 . 3 2 2}$ & - & $\mathbf{- 0 . 3 6 7}$ \\
\hline
\end{tabular}

Table. 2.Change in Gibbs free energy of formation, $\Delta G_{f}(\mathrm{kcal} / \mathrm{mol})$, equilibrium interatomic distances $(\AA)$ between the oxygen atoms, $r(\mathrm{O}=\mathrm{O})$, between the oxygen atoms and the carbon atoms, $r(\mathrm{O}-\mathrm{C})$, in the dimers and dimer- $\mathrm{O}_{2}$ complexes.

\begin{tabular}{|c|c|c|c|c|c|}
\hline & Binding site $\left(C_{x}-C_{y}\right)$ & $\Delta \mathrm{G}_{f}$ & $r(\mathrm{O}=\mathrm{O})$ & $r\left(\mathrm{O}-\mathrm{C}_{\mathrm{x}}\right)$ & $r\left(\mathrm{O}-\mathrm{C}_{\mathrm{y}}\right)$ \\
\hline $\mathrm{O}_{2}$ & - & - & 1.205 & - & - \\
\hline \multirow{2}{*}{$2 \mathrm{ANSA}-\mathrm{O}_{2}$} & $\mathrm{C}_{8}-\mathrm{C}_{9}$ & 10.73 & 1.498 & 1.490 & 1.467 \\
\hline & $\mathrm{C}_{14}-\mathrm{C}_{15}$ & 10.89 & 1.499 & 1.495 & 1.467 \\
\hline \multirow[t]{2}{*}{4 ANSA-O ${ }_{2}$} & $\mathrm{C}_{8}-\mathrm{C}_{9}$ & 12.99 & 1.500 & 1.489 & 1.467 \\
\hline & $\mathrm{C}_{14}-\mathrm{C}_{15}$ & 14.94 & 1.497 & 1.484 & 1.466 \\
\hline \multirow[t]{2}{*}{ 5ANSA-O ${ }_{2}$} & $\mathrm{C}_{8}-\mathrm{C}_{9}$ & 14.90 & 1.497 & 1.484 & 1.466 \\
\hline & $\mathrm{C}_{14}-\mathrm{C}_{15}$ & 12.68 & 1.497 & 1.484 & 1.466 \\
\hline \multirow[t]{2}{*}{8 ANSA-O ${ }_{2}$} & $\mathrm{C}_{8}-\mathrm{C}_{9}$ & 10.71 & 1.492 & 1.545 & 1.455 \\
\hline & $\mathrm{C}_{14}-\mathrm{C}_{15}$ & 11.14 & 1.497 & 1.535 & 1.455 \\
\hline
\end{tabular}

The electrocatalytic activities for ORR of GC/rGO, GC/poly(8-ANSA), GC/poly(8ANSA)/rGO and GC/rGO/poly(8-ANSA) were studied using linear sweep voltammetry (LSV) in $\mathrm{N}_{2}$ and $\mathrm{O}_{2}$ saturated $0.1 \mathrm{M} \mathrm{KOH}$ solution and compared with each other in Figure 3c. Background corrected polarization curves (Figure 3c) at $1600 \mathrm{rpm}$ shows GC/poly(8ANSA)/rGO has the highest current density and more positive onset potential than GC/poly(8ANSA) as well as $\mathrm{GC} / \mathrm{rGO}$, which demonstrate the good electrocatalytic activity of $\mathrm{GC} / \mathrm{poly}(8-$ ANSA)/rGO. GC/rGO/poly(8-ANSA) composite exhibits lower electrocatalytic activity towards ORR. At $-0.6 \mathrm{~V}$ for instance, the current density recorded for ORR on the GC/poly(8ANSA)/rGO is $2.27 \mathrm{~mA} \mathrm{~cm}^{-2}$ which is much higher than GC/rGO/poly(8-ANSA) $(1.44 \mathrm{~mA}$ $\mathrm{cm}^{-2}$ ). This is attributed to oxidation potential applied to electropolymerized 8-ANSA on 
$\mathrm{GC} / \mathrm{rGO}$ to produce $\mathrm{GC} / \mathrm{rGO} /$ poly(8-ANSA) which could also possibly oxidize the previously synthesized rGO forming less conductive graphene oxide (GO).

The kinetics of the ORR activity of $\mathrm{GC} / \mathrm{poly}(8-\mathrm{ANSA}) / \mathrm{rGO}$ were further investigated at different electrode rotational rates from 400 to $2500 \mathrm{rpm}$ in $0.1 \mathrm{M} \mathrm{KOH}$ as shown in Figure $5 \mathrm{a}$. The onset of the $\mathrm{O}_{2}$ reduction wave on GC/poly(8-ANSA)/rGO begins at a potential close to $-0.21 \mathrm{~V}(v s \mathrm{Ag} / \mathrm{AgCl})$. The current density increased when the rotational rates were increased from $400 \mathrm{rpm}$ to $2500 \mathrm{rpm}$, indicating that the ORR is controlled by mass diffusion [13].

Koutecky-Levich (K-L) equation was applied in mixed kinetic -diffusion controlled region in order to estimate the transferred electron number per oxygen molecule involved in the ORR. The $\mathrm{K}-\mathrm{L}$ equation can be represented as follows:

$\frac{1}{J}=\frac{1}{J_{L}}+\frac{1}{J_{k}}=\frac{1}{0.2 \mathrm{nFC} C_{o} D_{o}^{2 / 3} v^{-1 / 6} \omega^{1 / 2}}+\frac{1}{n F k_{O_{2}} C_{O_{2}} \Gamma}=\frac{1}{J_{L}}+\frac{1}{n F k_{f} C_{O_{2}}}=$

where $J$ is the measured current density, $J_{K}$ and $J_{L}$ are the kinetic and diffusion-limiting current densities, $\omega$ is the angular velocity of the disk (in $\mathrm{rpm}$ ), $n$ is the overall number of electrons transferred in oxygen reduction, $F$ is the Faraday constant $\left(F=96485 \mathrm{C} \mathrm{mol}^{-1}\right), C_{0}$ is the bulk concentration of $\mathrm{O}_{2}\left(1.2 \times 10^{-3} \mathrm{M}\right), D_{0}$ is the diffusion coefficient of oxygen $\left(1.9 \times 10^{-5} \mathrm{~cm}^{2} \mathrm{~s}^{-1}\right)$, $v$ is the kinematic viscosity of the electrolyte $\left(v=0.01 \mathrm{~cm}^{2} \mathrm{~s}^{-1}\right), k_{O_{2}}$ is the electron transfer rate constant, $k_{f}$ is the heterogeneous rate constant, and $\Gamma$ is the surface coverage of the catalyst on GC electrode as given in Table 3. The surface coverage $\Gamma$ can be evaluated from the equation $\Gamma=Q / n F A$, where $Q$ is the charge obtained by integrating the cathodic peak under the background correction at low scan rate from Figure $3 \mathrm{a}[2,36]$.

K-L plots $\left(J^{-1} v s \omega^{-1 / 2}\right)$ for $\mathrm{GC} / \mathrm{poly}(8$-ANSA)/rGO (Figure $5 \mathrm{~b}$ ) are parallel and linear, confirming that ORR follows first-order kinetics with respect to $\mathrm{O}_{2}$ molecule. Furthermore, the plots do not pass through the origin indicating a mixed kinetic -diffusion controlled mechanism $[15,29]$. The number of electrons transferred (n) and $J_{K}$ can be obtained from the slope and intercept of the K-L plots [30]. The heterogeneous rate constants $\left(\mathrm{k}_{\mathrm{f}}\right)$ for the reduction of oxygen were calculated from $\mathrm{J}_{\mathrm{K}}$ and reported in Table 3. The ORR occurs either via direct four electrons pathway where $\mathrm{O}_{2}$ is reduced to $\mathrm{OH}^{-}$or 2-electron reduction pathway, where $\mathrm{O}_{2}$ is reduced to $\mathrm{HO}_{2}^{-}$[4]. The electron transfer number were calculated using $\mathrm{K}-\mathrm{L}$ plots over the potential region of -0.36 to $-0.43 \mathrm{~V}$ to be $2.8-2.5$ for $\mathrm{GC} / \mathrm{poly}(8-\mathrm{ANSA}) / \mathrm{rGO}, 2-2.13$ for $\mathrm{GC} / \mathrm{rGO}$, and $1.8-2.5$ for $\mathrm{GC} / \mathrm{poly}(8-\mathrm{ANSA})$. These result demonstrated that the ORR process at the $\mathrm{GC} / \mathrm{poly}(8$ ANSA) and $\mathrm{GC} / \mathrm{rGO}$ composite proceed with two electrons $\left(2 \mathrm{e}^{-}\right)$pathway with the formation of $\mathrm{HO}_{2}^{-}$but a mixture of $\mathrm{HO}_{2}^{-}$and $\mathrm{OH}^{-}$for $\mathrm{GC} / \mathrm{poly}(8-\mathrm{ANSA}) / \mathrm{rGO}$ [4]. The direct, green and in situ electroreduction of $\mathrm{O}_{2}$ dissolved in alkaline media to $\mathrm{HO}_{2}^{-}$on $\mathrm{GC} / \mathrm{rGO}$ and $\mathrm{GC} / \mathrm{poly}(8-$ ANSA) electrodes is an attractive alternative to the current anthraquinone-based industrial production of $\mathrm{H}_{2} \mathrm{O}_{2}$, which produces a large number of chemical pollutants in a multistep energy intensive processes [39].

The RRDE was used further to evaluate the ORR pathway by monitoring the intermediate peroxide species of $\mathrm{HO}_{2}^{-}$generated at the disk electrode in the alkaline medium during the ORR process at the GC/poly(8-ANSA)/rGO, GC/rGO, and GC/poly(8-ANSA) electrodes. As shown in Figure 5d, all three catalysts generate ring currents over the potential range from -0.2 to -0.7 $\mathrm{V}$ for ORR. The electron transfer numbers (n) derived from RRDE result using equation 2 [5] over the potential range of -0.36 to $-0.43 \mathrm{~V}$ to be $2.1-2.18$ for GC/poly(8-ANSA), $2.14-2.15$ for $\mathrm{GC} / \mathrm{rGO}$, and $2.76-2.82$ for GC/poly(8-ANSA)/rGO, being consistent with the RDE results. Hence, the $\mathrm{HO}_{2}^{-}$yields determined using equation 3 [5] for GC/poly $(8-\mathrm{ANSA}) / \mathrm{rGO}(57 \%)$ significantly lower than $\mathrm{GC} / \mathrm{rGO}(93 \%)$, and GC/poly(8-ANSA) (92\%). All these values demonstrate the synergistically enhanced electrocatalytic efficiency of the composite (GC/poly(8-ANSA/rGO). 

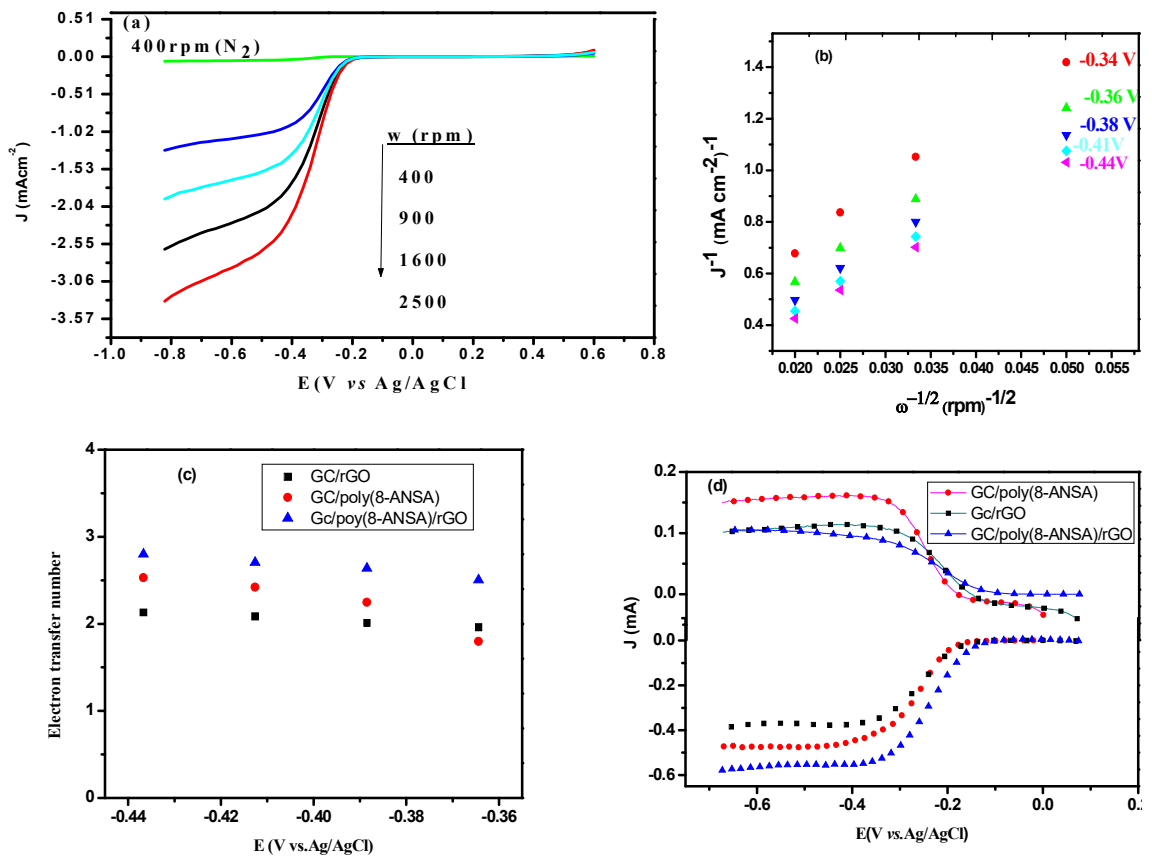

Figure 5. (a): Linear sweep voltammograms of GC/poly(8-ANSA)/rGO at different rotation speeds at a scan rate of $20 \mathrm{mV} \mathrm{s}^{-1},(\mathrm{~b})$ : K-L plots $\left(J^{1} v s \omega^{-1 / 2}\right)$ at different electrode potentials in $0.1 \mathrm{M} \mathrm{KOH},(\mathrm{c})$ : Electron transfer number as a function of potential of $\mathrm{GC} / \mathrm{rGO}$, GC/poly(8-ANSA), and GC/poly(8-ANSA)/rGO, and (d) RRDE voltammograms of GC/rGO, GC/poly(8-ANSA), and GC/poly(8-ANSA)/rGO at 1600 $\mathrm{rpm}$. The ring current was polarized at $+1.0 \mathrm{~V}$.

$n=\frac{4 i_{d}}{i_{d}+\frac{i_{r}}{N}}$

$\% \mathrm{HO}_{2}^{-}=\frac{\mathbf{2 0 \mathbf { a } _ { r }}}{i_{d+\frac{i_{r}}{N}}^{N}}$

$N=-\frac{i_{r}}{i_{d}}$

where $\mathrm{N}$ is the collection efficiency of the rotation ring disk electrode (RRDE), and $i_{d}$ and $i_{r}$ are the disk and ring electrode currents, respectively.

The logarithm of $\mathrm{J}_{\mathrm{k}}$ was plotted against the potential to analyze the Tafel behavior for GC/poly(8-ANSA)/rGO, GC/poly(8-ANSA), and GC/rGO catalysts. The reaction kinetics can be evaluated using Tafel equation (5) [40]:

$\log J_{k}=-\frac{1}{b}\left(\mathrm{E}-E^{0}\right)+\log J_{0}$

$\mathrm{b}=\frac{2: 30 \mathrm{RT}}{\alpha n F} \ldots \ldots$

where $E$ is the measured potential of the working electrode, $E^{0}$ is the equilibrium open-circuit potential, $\mathrm{b}$ is the Tafel slope, $\mathrm{R}$ is gas constant $\left(8.314 \mathrm{~J} \mathrm{~mol}^{-1} \mathrm{~K}^{-1}\right)$; $\mathrm{T}$ is the Kelvin temperature $(298.15 \mathrm{~K}), \mathrm{J}_{\mathrm{k}}$ is the kinetics current density, and $\mathrm{J}_{0}$ is the exchange current density.

Bull. Chem. Soc. Ethiop. 2019, 33(2) 
Using equation 5 , the high value of $\mathrm{J}_{0}$ and low value of $\mathrm{b}$ will give high $\mathrm{J}_{\mathrm{k}}$ value under same overpotential $\left(\mathrm{E}-\mathrm{E}_{0}\right) . \mathrm{J}_{0}$ is a key parameter which reflects intrinsic rates of electron transfer between the solution and the electrode. It can be used to judge the catalytic efficiency of materials [40, 41].

The Tafel plots clearly show the electrocatalytic activity differences among the electrode materials. At $-0.36 \mathrm{~V}$, for instance, the kinetic current density of ORR on the GC/poly $(8$ ANSA)/rGO is $7.53 \mathrm{~mA} \mathrm{~cm}{ }^{-2}$, which is significantly higher than $\left.\mathrm{GC} / \mathrm{rGO}(0.58 \mathrm{~mA} \mathrm{~cm})^{-2}\right)$ and GC/poly(8-ANSA) (0.82 $\left.\mathrm{mA} \mathrm{cm}^{-2}\right)$. Tafel slopes and exchange current density were estimated from the linear portion of the Tafel plot at low current density region (Figure 6a) and presented in Table 3. Therefore, incorporation of 8-ANSA between GC and $\mathrm{rGO}$ reduces the Tafel slope from $74 \mathrm{mV} \mathrm{dec}^{-1}$ to $68 \mathrm{mV} \mathrm{dec}^{-1}$ indicating more favorable kinetics for ORR [42]. The exchange current densities $\left(J_{o}\right)$ were estimated from the intercept of a linear portion of the Tafel plots [41]. The $J_{o}$ values for $\mathrm{GC} / 8-\mathrm{ANSA} / \mathrm{rGO}$ much higher than that of $\mathrm{GC} / \mathrm{rGO}$ and $\mathrm{GC} / 8-\mathrm{ANSA}$ showing an improved catalytic efficiency of the composite for ORR.

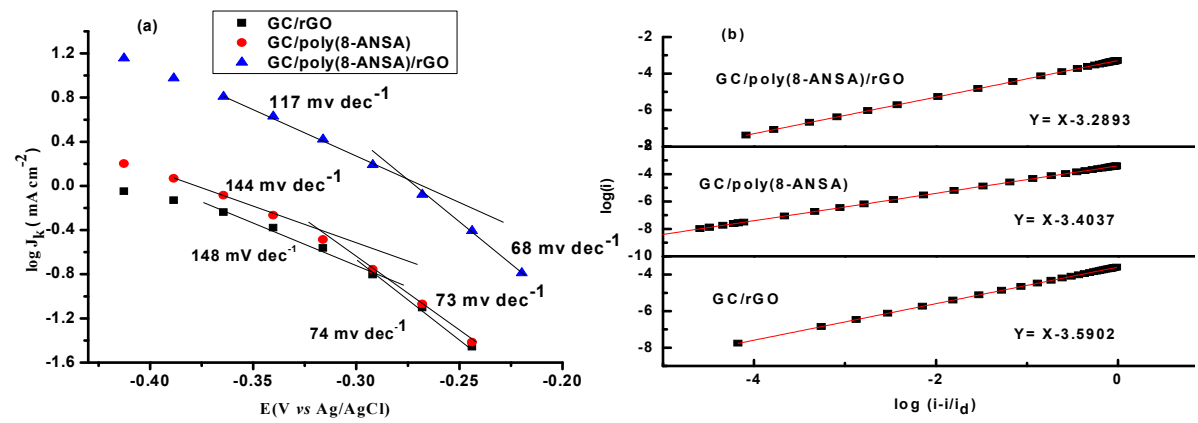

Figure 6. (a) Tafel plots for the ORR at GC/poly(8 ANSA)/rGO( $\mathbf{\Delta}), \mathrm{GC} / \operatorname{poly}(8-\mathrm{ANSA})(\bullet)$, and $\mathrm{GC} / \mathrm{rGO}(\boldsymbol{\square})$ at an electrode rotation rate of $1600 \mathrm{rpm}$.(b)reaction order plot for oxygen reduction reaction on $\mathrm{GC} / \mathrm{rGO}, \mathrm{GC} / \mathrm{poly}(8-\mathrm{ANSA})$, and $\mathrm{GC} / \mathrm{poly}(8-\mathrm{ANSA}) / \mathrm{rGO}$ (the slope stands for the reaction order number).

The reaction order (m) of ORR on GC/rGO, GC/poly(8-ANSA), and GC/poly(8-ANSA)/rGO catalysts was checked further by plotting $\log$ i versus $\log [(\mathrm{i}-\mathrm{i} / \mathrm{id})]$ [43]. From Figure $6 \mathrm{~b}$ and Table 3 , the first order dependence of the kinetics of the ORR was performed on GC/rGO, GC/poly(8ANSA), and GC/poly(8-ANSA)/rGO.

Table 3. Tafel slopes and exchange current densities for the ORR at GC/rGO, GC/8-ANSA, and GC/8ANSA/rGO

\begin{tabular}{|c|c|c|c|c|c|c|c|c|}
\hline Catalyst & $\mathrm{m}$ & $\mathrm{K}-\mathrm{L}$ & $\begin{array}{l}\text { n } \\
\text { RRDE }\end{array}$ & $\alpha$ & $\begin{array}{c}\mathrm{b} \\
\left(\mathrm{mV} \operatorname{dec}^{-1}\right)\end{array}$ & $\begin{array}{c}J_{0} \\
\left(\mathrm{~mA} \mathrm{~cm}^{-2}\right)\end{array}$ & $\begin{array}{c}\Gamma \\
\left(\mathrm{mol} \mathrm{cm}^{-2}\right)\end{array}$ & $\begin{array}{c}k_{f} \\
\left(\mathrm{~cm} \mathrm{~s}^{-1}\right)\end{array}$ \\
\hline $\mathrm{GC} / \mathrm{rGO}$ & 1 & 2.04 & 2.01 & 0.8 & 74 & $1.76 \times 10^{-5}$ & $1.87 \times 10^{-8}$ & $2.7 \times 10^{-3}$ \\
\hline GC/8-ANSA & 1 & 2.3 & 2.12 & 0.81 & 73 & $1.78 \times 10^{-5}$ & $2.01 \times 10^{-8}$ & $3.8 \times 10^{-3}$ \\
\hline $\mathrm{GC} / 8-\mathrm{NSA} / \mathrm{rGO}$ & 1 & 2.7 & 2.8 & 0.87 & 68 & $9.58 \times 10^{-5}$ & $2.36 \times 10^{-8}$ & $3.5 \times 10^{-2}$ \\
\hline
\end{tabular}

The value of $k_{\mathrm{f}}$ depends on the intrinsic activity of the catalyst sites and the surface concentration of catalyst sites [37]. In the present work, the surface coverage of all the catalyst films have the same order of magnitude $\left(10^{-8} \mathrm{~mol} \mathrm{~cm}^{-2}\right)$ therefore the surface concentration of the catalysts assumed to be constant. GC/rGO, GC/poly(8-ANSA), and GC/poly(8-ANSA)/rGO yielded a slope of 74, 73, and $68 \mathrm{mV} \mathrm{dec}^{-1}$, respectively, at low current density and the Tafel 
slopes increase at a higher current density. A Tafel slope of $60 \mathrm{mV} \mathrm{dec}^{-1}$ at $25^{\circ} \mathrm{C}$ would suggest a fast electron transfer reaction followed by a rate-determining chemical step. Furthermore, an increase in Tafel slope at more negative potential in alkaline solution would also attribute to the chemical rate-determining step [37, 44]. A mechanistic scheme that is consistent with these results is as follows:

$$
\begin{aligned}
& \mathrm{GC} / \mathrm{Q}+e^{-} \rightarrow \mathrm{GC}^{-} \mathrm{Q}^{-} \\
& \mathrm{GC} / \mathrm{Q}^{-}+\mathrm{O}_{2} \rightarrow \mathrm{GC} / \mathrm{Q}-\mathrm{O}_{2}^{-} \\
& \mathrm{GC} / \mathrm{Q}-\mathrm{O}_{2}^{-}+\mathrm{H}_{2} \mathrm{O}+e^{-} \rightarrow \mathrm{GC} / \mathrm{Q}+\mathrm{HO}_{2}^{-}+\mathrm{OH}^{-} \\
& \mathrm{HO}_{2}^{-}+\mathrm{H}_{2} \mathrm{O}+2 e^{-} \rightarrow 3 \mathrm{OH}^{-}
\end{aligned}
$$

where, GC/Q is glassy carbon modified with rGO, poly(8-ANSA) or poly(8-ANSA)/rGO. Reaction 8 is the rate determining slow chemical step occurred after a fast electron transfer step (reaction 7).

The specific performance of GC/poly(8-ANSA)/rGO is compared with similar other values reported in the literature in Table 4.

Table 4. Comparison of materials and specific performance of the catalyst in $0.1 \mathrm{M} \mathrm{KOH}$.

\begin{tabular}{|l|c|c|c|c|c|}
\hline Catalyst & $\begin{array}{c}\text { Peak potential } \\
(v s . \mathrm{Ag} / \mathrm{AgCl})(\mathrm{V})\end{array}$ & $b\left(\mathrm{mv} \mathrm{dec}^{-1}\right)$ & $\alpha$ & $J^{o}\left(\mathrm{~mA} \mathrm{~cm}^{-2}\right)$ & Reference \\
\hline rGO-DAB & -0.28 & 62 & - & - & 5 \\
\hline PEDOT:PSS/rGO & -0.27 & - & - & - & 13 \\
\hline Py-EGO & -0.28 & - & - & - & 7 \\
\hline Fe-N/ rGOHN500 & - & 88 & 0.67 & $2 \times 10^{-5}$ & 31 \\
\hline Fe-N/rGOsonic & - & 86 & 0.69 & $2 \times 10^{-5}$ & 31 \\
\hline (G-dye-FeP)n MOF & -0.23 & - & - & - & 36 \\
\hline CNx/graphene & -0.19 & - & - & - & 45 \\
\hline PPy/rGO & -0.30 & - & - & - & 45 \\
\hline N -doped graphene & -0.32 & - & - & - & 46 \\
\hline GC/poly(8ANSA)/rGO & -0.29 & 68 & 0.87 & $9.58 \times 10^{-5}$ & This work \\
\hline
\end{tabular}

-DAB-1,4-diaminobutane, -Py-EGO-pyridine functionalized graphene nanosheets, -HN500- thermal annealed under $\mathrm{H}_{2}-\mathrm{N}_{2}$ atmosphere at $500{ }^{\circ} \mathrm{C}$, -Sonic-ultrasonication, -(G-dye-FeP)n MOF-dye functionalized rGOiron-porphyrin metal-organic framework, -Carbon-nitrogen $(x=0.15)$, -PPy-polypyrrole.

\section{CONCLUSION}

We applied quantum mechanical (QM) calculations to evaluate the catalytic activity of poly $(8-$ amino-2-naphthalene sulfonic acid), poly(2-amino-1-naphthalene sulfonic acid, poly(5-amino-1naphthalene sulfonic acid), and poly(4-amino-1-naphthalene sulfonic acid). Our investigations have shown that the existence of electrocatalytic activity for oxygen reduction reaction on different amino substituted naphthalene sulfonic acid. QM calculations predict a much better catalytic activity for poly(8-amino-2-naphthalene sulfonic acid). The preparation and characterization of 8-ANSA, 2-ANSA, 5-ANSA, and 4-ANSA with rGO as composite electrocatalytic material for oxygen reduction reaction were investigated electrochemically. The polymerization of all monomer and conversion of $\mathrm{GO}$ to $\mathrm{rGO}$ was done using cyclic voltammetry. The composites of poly(8-ANSA) and $\mathrm{rGO}$ was found as a promising material for oxygen reduction reaction due to its better electrocatalytic performance. Analysis of the electrochemical reduction of oxygen at GC/poly(8-ANSA)/rGO exhibits enhanced catalytic activity with high exchange current density and high kinetic current towards oxygen reduction reaction in alkaline solution compared to $\mathrm{GC} / \mathrm{rGO}$ and $\mathrm{GC} /$ poly(8-ANSA). $\mathrm{GC} / \mathrm{rGO}$ and 
GC/poly(8-ANSA) have good applicability in catalyzing the reduction of oxygen for in situ production of $\mathrm{H}_{2} \mathrm{O}_{2}$.

\section{ACKNOWLEDGMENTS}

The authors are grateful for the International Science Program, Upsala University Sweden for financial support and CERIT-SC (CERIT Scientific Cloud) of the Czech Republic for the computational resources.

\section{REFERENCES}

1. Yang, J.; Sun, H.; Liang, H.; Ji, H.; Song, L.; Gao, C.; Xu, H. A highly efficient metal-free Oxygen Reduction electrocatalyst assembled from carbon nanotubes and graphene. $A d v$. Mater. 2016, 28, 4606-4613.

2. Kumar, S.A; Chen, S. Electrocatalytic reduction of oxygen and hydrogen peroxide at poly $(p-$ aminobenzene sulfonic acid)-modified glassy carbon electrodes. J. Mol. Catal. A: Chem. 2007, 278, 244-250.

3. Gong, Z.; Zhang, G.; Wang S. Electrochemical reduction of oxygen on anthraquinone /carbon nanotubes nanohybrid modified glassy carbon electrode in neutral media. J. Chem. 2013, 2013, 1-9.

4. Tang, J.; Ou, Z.; Guo, R.; Fang, Y.; Huang, D.; Zhang, J.; Zhang, J.; Guo, S.; McFarland, F.M.; Kadish, K.M. Functionalized cobalt triarylcorrole covalently bonded with graphene oxide: A selective catalyst for the two- or four-electron reduction of oxygen. Inorg. Chem. 2017, 56, 8954-8963.

5. Ahmed, M.S; Kim, Y. Amide-functionalized graphene with 1,4-diaminobutane as efficient metal-free and porous electrocatalyst for oxygen reduction. Carbon 2017, 111, 577-586.

6. Li, Q.; Cao, R.; Cho, J.; Wu, G. Nanocarbon electrocatalysts for oxygen reduction in alkaline media for advanced energy conversion and storage. Adv. Energy Mater. 2014, 4, 1301415. DOI: 10.1002/aenm.201301415.

7. Ensafi, A.A.; Jafari-Asl, M.; Rezaei, B. Pyridine-functionalized graphene oxide, an efficient metal free electrocatalyst for oxygen reduction reaction. Electrochim. Acta 2016, 194, 95103.

8. Tong, X.; Wei, Q.; Zhan, X.; Zhang, G.; Sun, S. The new graphene family materials: Synthesis and applications in oxygen reduction reaction. Catalysts 2017, 7, 1-26.

9. Lehtimäki, S.; Suominen, M.; Damlin, P.; Tuukkanen, S.; Kvarnström, C.; Lupo, D. Preparation of supercapacitors on flexible substrates with electrodeposited EDOT/graphene composites. ACS Appl. Mater. Interfaces 2015, 7, 22137-22147.

10. Bikkarolla, S.K.; Cumpson, P.; Joseph, P.; Papakonstantinou, P. Oxygen reduction reaction by electrochemically reduced graphene oxide. Faraday Discus 2014, 173, 415-428.

11. Kumar, G.G.; Kirubaharan, C.J.; Udhayakumar, S.; Karthikeyan, C.; Nahm, K.S. Conductive polymer/graphene supported platinum nanoparticles as anode catalysts for the extended power generation of microbial fuel cells. Ind. Eng. Chem. Res. 2014, 53, 1688316893.

12. Geto, A; Brett, C.M.A. Electrochemical synthesis, characterisation and comparative study of new conducting polymers from amino-substituted naphthalene sulfonic acids. J. Solid State Chem. 2016, 20, 2969-2979.

13. Zhang, M.; Yuan, W.; Yao, B.; Li, C.; Shi, G. Solution-Processed PEDOT: PSS-graphene composites as electrocatalyst for oxygen reduction reaction. ACS Appl. Mater. Interfaces 2014, 6, 3587-3593.

14. Unni, S.M.; Devulapally, S.; Karjule, N.; Kurungot, S. Graphene enriched with pyrrolic coordination of the doped nitrogen as an efficient metal-free electrocatalyst for oxygen reduction. J. Mater. Chem. 2012, 22, 23506-23513. 
15. Mutyala, S; Mathiyarasu, J. Graphene-polyaniline nanofiber composite as electrocatalyst for oxygen reduction reaction in alkaline media. ECS Trans. 2015, 64, 33-42.

16. Huang, X.; Yin, X.; Yu, X.; Tian, J.; Wu, W. Preparation of nitrogen-doped carbon materials based on polyaniline fiber and their oxygen reduction properties. Colloids Surf. A 2018, 539, 163-170.

17. Zhou, X.; Qiao, J.; Yang, L.; Zhang, J. A review of graphene-based nanostructural materials for both catalyst supports and metal-free catalysts in PEM fuel cell oxygen reduction reactions. Adv. Energy Mater 2014, 4, 1301523. DOI: 10.1002/aenm.201301523.

18. Zewde, B.W; Admassie, S. Electrocatalysis of oxygen reduction at poly(4-amino-3hydroxynaphthalene sulfonic acid) and platinum loaded polymer modified glassy carbon electrodes. J. Power Sources 2012, 216, 502-507.

19. Shahriary, L; Athawale, A.A. Graphene oxide synthesized by using modified Hummers approach. Int. J. Renew. Energy Environ. Eng. 2014, 2, 58-63.

20. Shao, Y.; Wang, J.; Engelhard, M.; Wang, C.; Lin, Y. Facile and controllable electrochemical reduction of graphene oxide and its applications. J. Mater. Chem. 2010, 20, 743-748.

21. Garsany, Y.; Baturina, O.A.; Lyons, K.E.; Kocha, S.S. Experimental methods for quantifying the activity of platinum electrocatalysts for the oxygen reduction reaction. Anal. Chem. 2010, 82, 6321-6328.

22. Frisch, M.J.; Trucks, G.W.; Schlegel, H.B.; Scuseria, G.E.; Robb, M.A.; Cheeseman, J.R.; Scalmani, G.; Barone, V.; Mennucci, B.; Petersson, G.A.; Nakatsuji, H.; Caricato, M.; Li, X.; Hratchian, H.P.; Izmaylov, A.F.; Bloino, J.; Zheng, G.; Sonnenberg, J.L.; Hada, M.; Ehara, M.; Toyota, K.; Fukuda, R.; Hasegawa, J.; Ishida, M.; Nakajima, T.; Honda, Y.; Kitao, O.; Nakai, H.; Vreven, T.; Montgomery, J.A., Jr.; Peralta, J.E.; Ogliaro, F.; Bearpark, M.; Heyd, J.J.; Brothers, E.; Kudin, K.N.; Staroverov, V.N.; Kobayashi, R.; Normand, J.; Raghavachari, K.; Rendell, A.; Burant, J.C.; Iyengar, S.S.; Tomasi, J.; Cossi, M.; Rega, N.; Millam, J.M.; Klene, M.; Knox, J.E.; Cross, J.B.; Bakken, V.; Adamo, C.; Jaramillo, J.; Gomperts, R.; Stratmann, R.E.; Yazyev, O.; Austin, A.J.; Cammi, R.; Pomelli, C.; Ochterski, J.W.; Martin, R.L.; Morokuma, K.; Zakrzewski, V.G.; Voth, G.A.; Salvador, P.; Dannenberg, J.J.; Dapprich, S.; Daniels, A.D.; Farkas, O.; Foresman, J.B.; Ortiz, J.V.; Cioslowski, J.; Fox, D.J. Gaussian 09, revision A.02, Gaussian, Inc.: Wallingford, CT; 2009.

23. Becke, A.D. Density-functional thermochemistry. III. The role of exact exchange J. Chem. Phys. 1993, 98, 5648-5652.

24. Lee, C.; Yang, W.; Parr, R. G. Development of the Colle-Salvetti correlation-energy formula into a functional of the electron density. Phys. Rev. B: Condens. Matter Mater. Phys. 1988, 37, 785-789.

25. Stephens, P.J.; Devlin, F.J.; Chabalowski, C.F.; Frisch, M.J. Ab Initio calculation of vibrational absorption and circular dichroism spectra using density functional force fields. $J$. Phys. Chem. 1994, 98, 11623-11627.

26. Krishnan, R.; Binkley, J.S.; Seeger, R.; Pople, J.A. Self-consistent molecular orbital methods. XX. A basis set for correlated wave functions. J. Chem. Phys. 1980, 72, 650-654.

27. Tomasi, J.; Mennucci, B.; Cammi, R. quantum mechanical continuum solvation models. Chem. Rev. 2005, 105, 2999-3094

28. Weinhold, F.; Landis, C.R. Natural bond orbitals and extensions of localized bonding concepts.Chem. Educ. Res. Pract. 2001, 2, 91-104.

29. Weinhold, F.; Landis, C.R. Discovering Chemistry with Natural Bond Orbitals, John Wiley and Sons: Hoboken, NJ; 2012.

30. Mao, X.; Yang, W.; He, X.; Chen, Y.; Zhao, Y.; Zhou, Y.; Yang, Y.; Xu, J. The preparation and characteristic of poly(3,4-ethylenedioxythiophene)/reduced graphene oxide nanocomposite and its application for supercapacitor electrode. J. Mater. Sci. Eng. B 2017, 216, $16-22$. 
31. Osmieri, L.; Monteverde Videla, A.H.A.; Specchia, S. The use of different types of reduced graphene oxide in the preparation of $\mathrm{Fe}-\mathrm{N}-\mathrm{C}$ electrocatalysts: Capacitive behavior and oxygen reduction reaction activity in alkaline medium. J. Solid State Electrochem. 2016, 20, 3507-3523.

32. Patnaik, S.G.; Vedarajan, R.; Matsumi, N. BIAN based electroactive polymer with defined active centers as metal-free electrocatalysts for oxygen reduction reaction (ORR) in aqueous and nonaqueous media. ACS Appl. Energy Mater. 2018, 1, 1183-1190.

33. Toh, S.Y.; Loh, K.S.; Kamarudin, S.K.; Daud, W.R.W. Graphene production via electrochemical reduction of graphene oxide:Synthesis and characterisation. Chem. Eng. J. 2014, 251, 422-434.

34. Kakhki, S.; Barsan, M.M.; Shams, E.; Brett, C.M.A. Development and characterization of poly(3,4-ethylenedioxythiophene)-coated poly(methylene blue)-modified carbon electrodes. Synth. Met. 2012, 161, 2718-2726.

35. Khomenko, V.G.; Barsukov, V.Z.; Katashinskii, A.S. The catalytic activity of conducting polymers towards oxygen reduction. Electrochim. Acta 2005, 50, 1675-1683.

36. Jahan, M.; Bao, Q.; Loh, K. Electrocatalytically active graphene-porphyrin MOF composite for oxygen reduction reaction. J. Am. Chem. Soc. 2012, 134, 6707-6713.

37. Zhang, G; Yang, F. Electrocatalytic reduction of dioxygen at glassy carbon electrodes modified with polypyrrole/anthraquinone disulphonate composite film in various $\mathrm{pH}$ solutions. Electrochim. Acta 2007, 52, 6595-6603.

38. Wondimu, B.; Admassie, S. Electrocatalytic reduction of oxygen at vapor phase polymerized poly(3,4-ethylenedioxidethiophene) modified glassy carbon electrode. Bull. Chem. Soc. Ethiop. 2012, 26, 449-454.

39. Wang, Y.; Yi, M.; Wang, K.; Song, S. Enhanced electrocatalytic activity for $\mathrm{H}_{2} \mathrm{O}_{2}$ production by the oxygen reduction reaction: Rational control of the structure and composition of multi-walled carbon nanotubes. Chin. J. Catal. 2019, 40, 523-533.

40. Hu, T.; Yin, Z.; Guo, J.; Wang, C. Synthesis of Fe nanoparticles on polyaniline covered carbon nanotubes for oxygen reduction reaction. J. Power Sources 2014, 272, 661-671.

41. Muthukrishnan, A.; Nabae, Y.; Hayakawa, T.; Okajima, T.; Ohsaka T. Fe-containing polyimide-based high-performance ORR catalysts in acidic medium: a kinetic approach to study the durability of catalysts. Catal. Sci. Technol. 2015, 5, 475-483.

42. Chen, S.; Duan, J.; Ran, J.; Jaroniec, M; Qiao, S. N-doped graphene film-confined nickel nanoparticles as a highly efficient three-dimensional oxygen evolution electrocatalyst. Energy Environ. Sci. 2013, 6, 3693-3699.

43. Stamenkovic, V.; Schmidt, T.J.; Ross, P.N.; Markovic, N.M. Surface segregation effects in electrocatalysis: Kinetics of oxygen reduction reaction on polycrystalline $\mathrm{Pt}_{3} \mathrm{Ni}$ alloy surfaces. J. Electroanal. Chem. 2003, 554-555, 191-199.

44. Hossain, M.S; Tryk, D; Yeager E. The electrochemistry of graphite and modified graphite surfaces: the reduction of $\mathrm{O}_{2}$. Electrochim. Acta 1989, 34, 1733-1737.

45. YanWen, M.; Rong, Z; Juan, L.; Tao, N.; Meng, L.; JinLei, Z.; Miao, F.; QuLi, F.; Zheng, $\mathrm{H}$.; Wei, H. Carbon nitrogen/graphene composite as metal-free electrocatalyst for the oxygen reduction reaction, Chinese Sci. Bull. 2011, 56, 3583-3589.

46. Yang, S.; Zhi, L.; Tang K.; Feng, X.; Maier, J.; Mullen K. Efficient synthesis of heteroatom ( $\mathrm{N}$ or $\mathrm{S}$ )-doped graphene based on ultrathin graphene oxide-porous silica sheets for oxygen reduction reactions. Adv. Funct. Mater. 2012, 22, 3634-3640. 